\title{
Territorio y memoria en el proceso de distritalización del Gran Pajonal (Ucayali-Perú)
}

\section{Territory and memory in the process of districtalization of Gran Pajonal (Ucayali-Peru)}

\author{
Liliana Fernández Fabián ${ }^{1 *}$
}

\section{RESUMEN}

El Gran Pajonal (Ucayali-Perú) es territorio originariamente ashéninka. Fue colonizado en un segundo intento en 1936 y desde hace 24 años, paralelamente al proceso de titulación de tierras indígenas, se busca que parte de su territorio sea declarado distrito y así acceder a un mayor presupuesto económico y servicios estatales. Este trabajo describe y examina el proceso de distritalización del Gran Pajonal desde sus inicios en un contexto de lucha entre ashéninkas y colonos por el territorio, el surgimiento de nuevas identidades y el papel que juega la memoria en las estrategias de los líderes indígenas para participar de la vida política en el Gran Pajonal. El propósito de este artículo es reflexionar acerca de cómo la memoria es silenciada y manipulada en la experiencia política indígena para llevar a cabo un proyecto de desarrollo occidental que puede debilitar las bases de la cultura ashéninka debido a que este fortalecerá el centralismo de la capital propuesta: Oventeni, el centro poblado colono.

Palabras clave: Memoria, colonización, identidad, territorio, ashéninka.

\begin{abstract}
The Gran Pajonal area (Ucayali-Peru) has always been an Asheninka territory. It was colonized in a second attempt in 1936. In parallel with the process of titling indigenous lands, asheninkas intend that part of its territory is declared district and thus they can have access to higher economic budget and state services. This paper describes and discusses the process of becoming a district that have lasted 24 years since its inception in a context of struggle for the territory between Asheninkas and settlers, the emergence of new identities and the role of memory in the strategies of indigenous leaders to participate in the political life in Gran Pajonal. The purpose is to think about how memory is silenced and manipulated in indian political experience to carry out a project of western development that can weaken the bases of Asheninka culture because this will strengthen Oventeni's centralism, the settler population center proposed as the capital.
\end{abstract}

Keywords: Memory, colonization, identity, territory, asheninka 


\section{INTRODUCCIÓN}

El Gran Pajonal se ubica en la parte suroeste de la región Ucayali (Perú), y limita con las regiones de Pasco y Junín. La población se autoidentifica como ashéninka. Actualmente, hay 6200 personas dispersadas en 48 comunidades nativas. En el centro, se halla el pueblo Oventeni fundado en 1936 por monseñor Francisco Irazola. Es habitado por colonos de origen andino, quienes fueron llevados ahí por los franciscanos. A 20 minutos de camino, en dirección oeste, se ubica la comunidad nativa Ponchoni, la más pequeña de las comunidades, pero que representa el centro de poder ashéninka, dado que ahí viven los principales líderes de la Organización Indígena del Gran Pajonal (OAGP); también se localiza la oficina donde celebran sus congresos y aniversarios y una de las tres escuelas bilingües de nivel secundario de toda la región.

La colonización, motivada por hacer del Gran Pajonal una zona ganadera, no fue un proceso pacífico, desde siempre hubo contiendas entre ashéninkas y mestizos, hecho que llevó a una disminución alarmante de la población indígena por los maltratos sufridos y las epidemias. El contacto impuesto e ineludible entre ambas culturas puso a los ashéninka en desventaja, debido a que los colonos se extendían en el territorio del Gran Pajonal sin mediar en que esas tierras ya tenían dueños. Además instauraron la esclavitud como institución al tener a los ashéninka sirviendo en sus chacras y hogares.

¿Cómo recuerdan los ashéninkas el periodo de la colonización? ¿Qué han aprendido sobre el contacto cultural? ¿Cómo manejan las políticas de desarrollo del Gran Pajonal? ¿Cómo interfiere la memoria en sus planes de desarrollo? Son preguntas que nos hacemos al reflexionar sobre un largo proceso de distritalización promovido por los líderes ashéninkas y las autoridades colonas de Oventeni.

La información que se detalla en este trabajo es el resultado de una profunda recopilación, sistematización y revisión del proceso de creación del distrito Gran Pajonal en la provincia de Atalaya, departamento de Ucayali (Perú), durante 24 años. La iniciativa de creación del distrito Gran Pajonal nace de los líderes indígenas que dirigen la Organización Ashéninka del Gran Pajonal, conocida por sus siglas como OAGP a inicios de la década de los noventa. Esta decisión nace y se impulsa de forma paralela al proceso de demarcación de las comunidades nativas.

Con este trabajo pretendemos: (1) reconocer el papel de la memoria o su silenciamiento para convertir el Gran Pajonal en un distrito; (2) comprender la importancia del territorio en la construcción identitaria de los pajonalinos (ashéninkas y colonos); (3) describir las relaciones de poder entre ashéninkas y colonos para superar las barreras socioculturales a lo largo de estos 24 años en que se ha llevado a cabo el proceso de distritalización del Gran pajonal. De este modo, queremos aportar a la etnografía ashéninka con datos históricos, de un proceso que hasta hoy no ha sido reportado en los estudios etnográficos sobre el Gran Pajonal.

\section{EL PAPEL DE LA MEMORIA EN EL CONFLICTO Y LA COHESIÓN SOCIAL}

Se distinguen dos grupos socioculturales entre los ashéninkas: uno que es tradicional, que mantiene un asentamiento disperso alejado del centro comunal donde la educación no formal es la que tiene mayor importancia y, por ende, la lengua originaria se ve fortalecida y sirve como vehículo para transmitir los conocimientos y normas sociales entre las generaciones. El otro grupo social está alrededor del centro poblado Oventeni. Estos ashéninkas ya no son tan competentes en la lengua originaria, los padres prefieren que sus hijos aprendan castellano y no les molesta que los docentes sean mestizos a pesar de que las escuelas son bilingües.

En este segundo grupo, se ha roto el vínculo generacional y la tradición oral ha pasado a segundo plano. Los relatos que los jóvenes escuchan de sus padres o abuelos son tomados como historias, cuentos. No lo asumen como hechos reales. La escuela como institución no es aliada de una construcción identitaria cultural que tenga bases sólidas de la cultura ashéninka, no recoge el conocimiento local, la historia oral del pue- 
blo, sino que ayuda a silenciarla. De ese modo, muchos ashéninkas no reconocen una historia reciente de colonización, de titulación de tierras, de explotación y subordinación.

El Gran Pajonal fue explorado inicialmente en 1733. Cuando los misioneros afirmaban haber convertido a 10000 indios ashéninkas, estalló una rebelión dirigida por Juan Santos Atahualpa. Se declaró indeseados a los misioneros y se pometió resistencia armada contra la opresión del virreinato español. Los efectos de la rebelión fueron de larga duración y la selva central permaneció bajo el control de los grupos indígenas locales por alrededor de cien años, pero en lo que respecta al Gran Pajonal, fue hasta 1936, casi doscientos años después, que los franciscanos intentan nuevamente reconquistar y recolonizar la zona. Desde entonces, el contacto impuesto e ineludible entre ambas culturas puso a los ashéninka en desventaja, porque los colonos instauraron la esclavitud como institución teniendo a los ashéninka sirviendo en sus chacras y hogares (Varese, 1973; Anderson, 2002; Hvalkof y Veber, 2005).

A medida que los ashéninka comenzaron a comprender lo que implicaba ser una comunidad, más y más grupos locales comenzaron a constituir comunidades y a solicitar su demarcación porque el conflicto con los colonos se aceleraba. La situación fue discutida con los líderes del Gran Pajonal y decidieron intentar obtener la demarcación y legalización de tantas comunidades como fuera posible ya que un control indígena del territorio aparecía como la solución inmediata. Después de violentos conflictos, se logró realizar el proceso de demarcación legal. Desde 1984 a 1988 se demarcaron y titularon 26 nuevas comunidades conformando un territorio indígena casi continuo circunscribiendo la zona colona (Hvalkof y Veber, 2005).

El silencio de su historia sobre la colonización por parte de los propios ashéninkas y de instituciones como la escuela, genera que las relaciones sociales sean desiguales en Oventeni, donde los mestizos tienen el control de la economía y siguen siendo los patrones de los ashéninkas invisibilizándolos a pesar de que son originarios de la zona y superan ampliamente a la población colona (6200 ashéninkas frente a 1600 mestizos).

Los ashéninkas permiten esto en su afán de tener mayor acceso a Oventeni, de apropiarse del lugar en términos simbólicos como ha ocurrido con la representación política a cargo de Miguel Camayteri, quien ha sido alcalde ashéninka en Oventeni durante varios periodos. Sin embargo, no debemos olvidar que a veces el silencio es una consecuencia de eventos muy traumáticos que generan vergüenza y condicionan las interrelaciones sociales (Crespo, 2014). Entonces, los líderes son quienes reviven la memoria colectiva en cada congreso o reunión importante, pero la subjetividad de las personas hace que esta memoria se consolide o silencie de acuerdo a sus necesidades e interrelaciones con los pobladores de Oventeni. Debemos comprender que estas relaciones son el resultado de experiencias donde los individuos que intervienen lo hacen por diversas razones y con fines particulares no necesariamente de solidaridad, porque las relaciones de poder son asimétricas (Bari, 2002). Estas condiciones sociales juegan un papel preponderante en los procesos de construcción de la memoria.

Como sostiene Augé (1998), el olvido es un recurso necesario para las sociedades, ya que ello permite vivir el presente. Realmente, los ashéninkas seleccionan de su memoria lo que es importante para ellos como individuos o colectividad de acuerdo con el sistema de valores del presente que está motivado por relaciones sociales de otro tipo, distintas al pasado. Hay otras necesidades en las familias, el acceso a la educación es primordial, tener dinero para alimentarse y vestir. Aun así, hay ashéninkas que viven de manera tradicional con una economía de subsistencia. El problema de este cambio social es saber qué tanta reflexión hay sobre un pasado que por transmitirse de manera oral es distorsionado o comprendido de modo fabulesco por las nuevas generaciones. La negación de la tradición oral en las escuelas ha provocado que muchos ashéninkas cuestionen su propia cultura y la construcción de su identidad cultural se debilite hasta el punto de querer 
asimilarse al mestizo.

Como consecuencia de este proceso, tenemos grosso modo dos grupos ashéninkas que construyen su memoria e identidad bajo distintos esquemas, pero también tenemos una generación de personas que nacieron en matrimonios mixtos, es decir uno de sus progenitores es ashéninka y el otro mestizo. Esta capacidad de construir más de una identidad se ve influenciada por la aceptación o rechazo de los grupos sociales y el autoestima de cada individuo. Así, algunos pueden haber pasado por crisis de identidad, pero siempre tienen la posibilidad de mantener ambos orígenes sobre todo si hablan la lengua indígena, de lo contrario será más difícil. Por eso, muchos se consideran mestizos y solo reconocen su vínculo con la cultura ashéninka por su ascendencia. Como indica Barrientos (2001), la identidad es una construcción interna del individuo.

\section{EL TERRITORIO COMO SOSTÉN DE LA IDENTIDAD}

El territorio es el espacio donde se produce la historia y se construye la memoria mediante la selección de hechos guardados en esta (Gómez, 2000). La memoria juega un papel importante en relación a la conceptualización del territorio como símbolo de identidad, ya que la construcción de las identidades colectivas está inmersa en un proceso histórico donde la territorialidad es el bien más preciado, que dota de sentido de pertenencia al ashéninka para que de ese modo reconstruya su pasado y cree una identidad que los diferencie de los colonos y ashéninkas, por ejemplo. Así lo entienden García y Surrallés (2009) cuando manifiestan que el hombre se apropia y controla un territorio de distintas formas y ello le confiere derechos sobre este espacio.

Giménez (2002) define el término identidad, desde una perspectiva relacional y situacional, como un conjunto de repertorios culturales que las personas interiorizan para delimitar simbólicamente sus fronteras y distinguirse de los demás en una situación determinada, todo ello en contextos históricamente especí- ficos y socialmente estructurados. El sujeto puede desarrollar identidades múltiples en aras de mantener su estatus social y poder interactuar debidamente en los distintos grupos sociales en los que sus actividades se desarrollan (Kuper, 2001).

La memoria se construye sobre la base de la experiencia de los sujetos y los antepasados de estos en sus respectivos territorios. Esta se hace explícita en la tradición oral y el discurso cotidiano, en cualquier reunión local o intercomunal. De este modo, se enfatiza el sentido de pertenencia al Gran Pajonal y se legitima su apropiación y defensa. Esto sienta las bases para la construcción identitaria de los ashéninkas, ya que el Gran Pajonal es el espacio histórico donde se hallan sus hogares, su trabajo, sus muertos; es la fuente de alimentos. Todo ashéninka sabe que debe defender su territorio de invasiones de foráneos: mestizos o asháninkas. Esta tensión permanente se refleja en las reuniones donde los líderes exigen a sus comuneros la protección de los límites de sus comunidades y la organización para las rondas. Los ashéninkas saben que su cultura depende de la protección de su base territorial (Kymlicka, 1996). El territorio es además un referente para distinguirse de otros ashéninkas. Por ejemplo, los ashéninkas del Gran Pajonal tienen modos de vida distintos al de los ashéninkas del Ucayali, quienes viven cerca al río.

En la actualidad, los jóvenes ashéninkas de las comunidades nativas alrededor de Oventeni están apropiándose de este lugar como espacio referencial prefiriéndolo por encima del Gran Pajonal. Ellos señalan vivir en Oventeni, viajar desde y hacia Oventeni. Igual ocurre con algunos adultos porque Oventeni es el centro, el lugar a donde deben llegar primero para ir a otras comunidades o salir a las ciudades. Este sentido de pertenencia a Oventeni ha posibilitado que los ashéninkas acepten que parte de su territorio se convierta en distrito y que no solo la capital sea Oventeni, sino que el nombre de este haya cambiado de Gran Pajonal a Gran Pajonal-Oventeni y Oventeni-Gran Pajonal recientemente.

Esta variación en la denominación del futuro distrito 
se ha observado en la documentación recopilada sobre su propuesta de creación, cuyo principal gestor es Ydelfondo Campos, un mestizo casado con una ashéninka. Los líderes pajonalinos han aceptado e impulsado este proyecto para obtener mayor presupuesto y lograr el desarrollo económico de la zona sin mediar en las consecuencias de esto para su cultura e identidad y para la cohesión social con las comunidades que se encuentran en los límites regionales, dado que algunas de ellas quedarían fuera del futuro distrito.

Sin embargo, el Gran Pajonal como referente va más allá de los límites jurisdiccionales políticos que se creen. Igual ocurre con el sentido de pertenencia a un determinado lugar. Entonces, el "ser ashéninka" es un concepto que va modificando su contenido, sus valores de acuerdo a las nuevas circunstancias. La construcción identitaria no entra en crisis por el territorio, porque el Gran Pajonal es un espacio histórico que trasciende los límites geográficos y se halla en la memoria del pajonalino. Por eso, cuando se creó la OAGP, comunidades que políticamente pertenecían a Pasco y Junín se adscribieron a esta organización. Aunque la organización indígena se ha debilitado, permanece vigente y es la única que representa a la mayoría de comunidades nativas ashéninkas de la zona. Su función y gran reto será mantener la cohesión y seguro será bajo la premisa de siempre: proteger los límites de las comunidades de posibles invasiones.

\section{CRONOLOGÍA DEL PROCESO DE DISTRITALIZACIÓN}

\section{Primera propuesta de creación del distrito del Gran Pajonal}

Tanto ashéninkas como colonos se atribuyen la idea original de convertir el Gran Pajonal en distrito. Miguel Camayteri Fernández y su hermano Pascual Camayteri Fernández sostienen que piensan en la creación de un distrito para combatir las desigualdades y la pobreza y comienzan a discutir esta posibilidad en los congresos indígenas de la OAGP cada año, y pedir a través de cartas y oficios ayuda para lograr esta meta que después de 24 años está llegando a concretarse.
En junio de 1992, la mayoría de habitantes del Gran Pajonal firman el memorial en el cual se solicita al Presidente de la Asamblea Regional de Ucayali la creación del distrito del Gran Pajonal con su capital Oventeni. Asimismo, se procede a realizar el estudio de factibilidad y la elaboración de un expediente técnico para la creación del distrito. Tanto los líderes colonos como los ashéninkas comprendían la importancia de que su espacio geográfico sea convertido en distrito y salir así del aislamiento en el que se encontraban. Por esos años, la trocha carrozable que unía Oventeni con Puerto Ocopa solo era transitable durante los meses de verano (mayo-setiembre), luego las lluvias impedían el paso y solo era posible entrar y salir por vía aérea. Los ashéninkas caminaban cinco días para salir de sus comunidades hacia las ciudades de Satipo o Atalaya. En consecuencia, la economía de la zona era prácticamente de subsistencia.

Como no había una respuesta de las autoridades regionales y provinciales, en junio de 1996, se crea el Comité de Fundación de la Distritalización del Gran Pajonal con su capital Oventeni. Solo dos miembros del comité eran ashéninkas pajonalinos: Pascual Camayteri, presidente de la OAGP, y Miguel Camayteri, presidente del Comité de Autodefensa. Estos líderes se encargarían de informar a los ashéninkas sobre los avances del proceso y también de exigir a las autoridades regionales y nacionales se atienda el pedido comunitario. Así, en nombre de las 35 CC.NN. ashéninkas que conformaban el Gran Pajonal en ese entonces, solicitan al presidente de la república, Alberto Fujimori, mediante una carta, que atienda los "proyectos de desarrollo" con el fin de luchar contra la pobreza extrema.

La solicitud de la distritalización continuaría durante los años 1997-1998. Dado que no se obtenía una respuesta formal de parte de las autoridades, se incluía, en los oficios a las autoridades provinciales, regionales y nacionales, la creación del distrito entre los principales problemas que la población esperaba atender. En febrero del 2000, la Municipalidad del Centro Poblado Menor Oventeni y la OAGP solicitan al Presidente del 
Concejo de Ministros apoyo para realizar este proyecto. La carta señala que no entienden cuál es el motivo del retraso de los trámites, ya que ocho años habían pasado desde la primera iniciativa. De ese mismo modo, en marzo del 2000, la MCPM Oventeni solicita a la presidenta del Consejo Transitorio de Administración Regional de Ucayali apoyo para la creación política del distrito.

En agosto del 2001, la OAGP nuevamente envía un memorial al Presidente de la República solicitando la apertura del Expediente Técnico del distrito de Gran Pajonal con su capital Oventeni. Además, se listan todos los oficios y cartas enviados a distintas instancias del gobierno entre 1992-2001, casi 10 años de gestión en que se solicitaba apoyo para crear un nuevo distrito. El 25 de julio del 2002 la Ley No 27795 de Demarcación y Organización Territorial se publica en el diario El Peruano (pág. 227020). Seis meses después, en enero del 2003, la OAGP envía un memorial al presidente del Gobierno Regional Ucayali solicitando la apertura del Expediente Técnico del distrito de Gran Pajonal con su capital Oventeni. Se anexan todos los oficios, cartas enviados a distintas instancias del gobierno entre 1992 y 2001.

En los siguientes años, se trabajaría la demarcación territorial de las comunidades ashéninkas. Como los problemas territoriales, de educación y salud eran más importantes para los ashéninkas, se desatendió el proceso de distritalización. El 7 de octubre del 2009, mediante Oficio $\mathrm{N}^{\circ} 360-2009-P C M-D N T D T$, se le informa al presidente de la OAGP, Cleofaz Quintori Soto, que la creación de nuevos distritos y provincias se encuentra suspendida a nivel nacional hasta el 31 de diciembre de 2011, según la Ley Nº 28920.

\section{Intervención política para la creación del distrito del Gran Pajonal}

Apenas se levanta la suspensión de creación de distritos, el 5 de enero del 2012, la Municipalidad del Centro Poblado Oventeni solicita al Gobierno Regional de Ucayali una Comisión Técnica para la elaboración del expediente de creación del distrito de Gran PajonalOventeni mediante Oficio $\mathrm{N}^{\circ}$ 005-2012-A-MCPO-
GR. De ese modo se retoma el pedido para convertir al Gran Pajonal en distrito, lo cual es una muestra de la espera de los pajonalinos y el accionar inmediato para continuar con su proyecto. Sin embargo, en marzo de ese año, las autoridades regionales señalan que el Centro Poblado Oventeni no amerita apertura de expediente técnico porque no tiene, según la Ley 27795, plan de desarrollo urbano, plaza pública, mercado de abastos (parte del mercado era empleado como vivienda), cementerio (formalizado), comisaría, saneamiento físico-legal de los predios urbanos, un mínimo de 1800 habitantes, entre otros requisitos para la creación de distritos que se detallan en los informes $\mathrm{N}^{\circ} 045$ 2012-GRU-P-GGR-GRPPyAT-SGOT y N No052012-GRU-P-GGR-GRPPyAT-SGOT-ardird, y el Oficio No 126-2012-GRU-P-GGR-GRPPyAT.

En los meses siguientes, las autoridades se encargarían de cumplir con los requisitos dispuestos por ley. De ese modo, se trabajaría en coordinación directa con la Municipalidad Provincial de Atalaya y el Gobierno Regional de Ucayali para modernizar y ordenar Oventeni. La OAGP, por su parte, solicita al RENIEC continuar con campañas para documentar a la población de las comunidades nativas. El 21 de mayo de 2013, se declara de urgente necesidad, para la provincia de Atalaya y región de Ucayali, la creación del distrito de Oventeni-Gran Pajonal en el Acuerdo No 014-2013CM de la Municipalidad Provincial de Atalaya. Así, el 1 de octubre del 2013, el Director de la Dirección Nacional Técnica de Demarcación Territorial de la PCM recomienda actualizar el Estudio del Diagnóstico y Zonificación (EDZ) de la provincia de Atalaya, con fines de demarcación. Entonces, el alcalde de la Municipalidad Provincial de Atalaya solicita lo propio al presidente del Gobierno Regional de Ucayali mediante Oficio No 306-2013-A-MPA.

Estos grandes logros fueron posibles gracias a la presencia política en la provincia de Atalaya de Denis Camayteri y Cleofaz Quintori en la Municipalidad Provincial, e Ydelfonso Campos en el Gobierno Regional. Su parentesco y objetivos en común permitieron que avancen en una misma dirección y que el 
proyecto entre en la agenda gubernamental y sea de interés primordial para el desarrollo de Ucayali.

El 10 de agosto del 2014, mediante Expediente $\mathrm{N}^{\mathrm{o}}$ 853-2014, se elige la junta directiva del Comité Pro Distrito Gran Pajonal Oventeni presidido por Ydelfondo Campos y se solicita su reconocimiento oficial a las autoridades locales. Una de las primeras medidas que toma el Comité es solicitar al RENIEC el Formato de lista de adherentes para Demarcación Territorial, y al GRU capacitación para el registro de firmas. Mientras tanto, el Presidente Regional de Ucayali remite el Estudio de Diagnóstico y Zonificación (EDZ) de la provincia de Atalaya al Director de la Dirección Nacional de Demarcación Territorial de la PCM mediante Oficio No 424-2014-GRU-P.

\section{Última etapa de la creación del distrito del Gran Pajonal}

Durante el año 2015, se concretarían algunas gestiones. Por ejemplo, en enero, mediante Oficio $\mathrm{N}^{\mathrm{o}} 167$ 2015-COFOPRI/OZUC, se informa que ya están listos 314 títulos de propiedad de Oventeni. En febrero, la MPA informa al Gerente Regional de Planeamiento, Presupuesto y Acondicionamiento Territorial del GRU que se ha aprobado el Plan de Ordenamiento Urbano del Centro Poblado de Oventeni, el cual tiene una vigencia de 10 años. Ese mismo mes, también se aprueba el Estudio de diagnóstico y zonificación (EDZ) de la provincia de Atalaya. En marzo, se apertura el expediente técnico de demarcación y organización territorial de la provincia de Atalaya y de la creación del distrito Gran Pajonal Oventeni.

El único problema por resolver hasta el momento sería la delimitación territorial de la provincia de Atalaya con la región Junín para lo cual se ha propuesto un referéndum entre la población, de modo que esta decida a cuál departamento pertenecer, si a Ucayali o Junín. Mientras esta consulta popular se hace realdiad, el proyecto se encuentra en la PCM y depende ahora de esta instancia legislativa que sea llevado al Congreso para su aprobación.

\section{CONCLUSIONES}

Con este artículo se ha tratado de revelar cómo los ashéninkas gestionan su memoria en relación al territorio para aceptar la distritalización del Gran Pajonal, un proyecto que aparentemente los subalterna porque la futura capital, Oventeni, adquiriría mayor notoriedad y fuerza económica centralizando la vida socioeconómica de los ashéninkas y dividiendo el territorio ancestral. Sin embargo, la unidad ashéninka no depende de factores geopolíticos, sino culturales. Por eso, hay ashéninkas que están en el territorio limítrofe de Pasco o en el territorio del distrito de Tahuanía y se consideran un mismo grupo social con los ashéninkas pajonalinos en tanto se comprendan lingüísticamente $\mathrm{y}$ tengan memoria de las relaciones intersociales como el trueque o los matrimonios que hasta la actualidad existen entre ellos. Aunque la economía puede afectar la unidad sociocultural, no ocurre así con los límites geográficos.

En este proceso de distritalización, la memoria se ha articulado con una lucha por la hegemonía, la defensa del territorio y la identidad de una nueva generación de personas que no se identifican como ashéninkas o mestizos sino como pajonalinos, trascendiendo las fronteras étnicas y construyendo una nueva sociedad. Estas personas son quienes realmente comprenden y apuestan por el proyecto de distritalización que los acercará más al Estado y a la economía nacional. El ashéninka tradicional no sabe o no le interesa el concepto de distrito porque ya tiene un plan de vida comunal que se rige por sus leyes tradicionales. Sin embargo, la pérdida de fuerza y, por lo tanto, legitimidad de la tradición oral - transmisión de la cosmovisión y de prácticas culturales vividas por sus antepasadossugiere que la situación actual en el Gran Pajonal respecto a este proceso y sus futuras consecuencias es resultado de una memoria frágil que olvida pronto, de la falta de reflexión sobre las experiencias pasadas y de un proceso de individualización, que si bien es todavía lento, pondría en peligro la colectividad como característica principal de la identidad ashéninka.

Los viejos líderes están cansados y no existe un liderazgo de renovación generacional que unifique. Por el 
contrario, en los últimos años los jefes de algunas comunidades han intentado formar nuevas organizaciones indígenas motivados por el manejo de fondos económicos que nunca llegaron y, en consecuencia, terminaron por disolver las organizaciones. Por otro lado, la autonomía comunal ha ocasionado que la economía la manejan los propios comuneros y sus proyectos de desarrollo sean discutidos solo en asambleas. Con esto la OAGP se ha debilitado y, quizás, esta sea la razón de apostar por una distritalización.

Dado que la identidad de los pajonalinos está estrechamente relacionada con el sentido de pertenencia a su territorio y específicamente a una comunidad, la distritalización no alteraría ese elemento constructivo de la identidad, pero sí generaría una mayor apreciación por Oventeni como punto de referencia y modelo socioestructural para sus comunidades nativas. En ese sentido, creemos que la posesión simbólica de la futura capital no se da por una reactivación de la memoria que indique algo así como "debemos recuperar un espacio originalmente ashéninka", sino por una cuestión de estatus social que hace que los ashéninkas se sientan “civilizados” por vivir como los mestizos, ya que producto de las experiencias de la colonización, han sido estigmatizados y discriminados siempre.

Finalmente, en este proceso se evidencia que los silencios permiten reconstruir una trayectoria común entre ashéninkas y mestizos y crear nuevas identidades en un nuevo contexto social. En tanto la memoria le da sentido a la acción de proteger el territorio y organizarse, para ello, en rondas, el silencio permite la reconciliación y comprensión de que el mestizo de Oventeni no es más el enemigo, de quien hay que defenderse, sino es un amigo, familiar, vecino, quien ofrece servicios, trabajo y también es pajonalino.

\section{REFERENCIAS BIBLIOGRÁFICAS}

Anderson, R. "Historias de cambio de los ashéninka". Lima (Perú), 2002.

Augé, M. "Las formas del olvido". Barcelona (España), 1998.

Bari, M. C. "La cuestión étnica: Aproximación a los conceptos de grupo étnico, identidad étnica, etnicidad y relaciones interétnicas". Cuadernos de Antropología Social, 16(2002): 149163.

Barrientos, I. "Identidad y lealtad: pueblos indígenas e inmigrantes". Papeles de cuestiones internacionales, 76(2001): 53-63.

Crespo, C. "Memorias de silencios en el marco de reclamos étnico-territoriales. Experiencias de despojo y violencia en la primera mitad del siglo XX en el Parque Nacional Lago Puelo (Patagonia, Argentina)". Cuicuilco, 21(2014): 165-187.

García, P. y A. Surrallés. “Antropología de un derecho. Libre determinación territorial de los pueblos indígenas como derecho humano". Copenhague (Dinamarca), 2009.

Giménez, G. "Paradigmas de la identidad”. En: A. Chihu Amparán (coord.), "Sociología de la identidad". México D.F. (México), UNAM, 2002: 35-62.

Gómez, J. "Lugares y Sentidos de la Memoria Indígena Paez". Convergencia. Revista de Ciencias Sociales, 7(2000): 167-202.

Hvalkof, S. y H. Veber. “Ashéninka”. En: Santos Granero, F. y Barclay, F. (eds.) Guía etnográfica de la Alta Amazonia. Volumen V: Campa Ribereños/Ashéninka. Institut français d'études andines - IFEA; Smithsonian tropical research institute. Perú, 2005.

Kuper, A. "Cultura, diferencia, identidad". En: Adam Kuper Cultura. Visión de los antropólogos. Barcelona (España), 2001:261-283.

Kymlicka, W. "La ciudadanía multicultural. Una teoría liberal de los derechos de las minorías". Editorial Paidós. México, 1996.

Varese, S. "La Sal de los Cerros". $2^{\circ}$ ed. Retablo de Papel. Lima (Perú), 1973. 